\title{
Jha Amit*
}

Dept. of ENT-HNS, National Medical College and Teaching Hospital, Birgunj-15, Parsa, Nepal.

Date of Submission : Feb 09, 2018

Received in Revised Form : Feb 21, 2018

Date of Acceptance : March 03, 2018

Date of Publishing : July 30, 2018

\section{ABSTRACT}

Background: Discharging ear is a common symptom among the patients presenting in ENT OPD for consultation. The commonest cause for discharging ear is chronic otitis media. Poverty, ignorance, crowded living conditions due to large families, poor sanitation, and lack of personal and environmental hygiene are some of the main factors behind the prevalence of chronic otitis media. National medical college and teaching hospital is a tertiary care center located in Birgunj metropolitan city in central Nepal. It caters to thousands of patients with discharging ear each year.

Methods: This qualitative, descriptive study was carried out in department of ENT-HNS at National Medical College and Teaching Hospital located Birgunj-15, Parsa, Province no. 2 of Nepal for duration of one year from August 1, 2014 to July 30, 2015. Two hundred and five (205) adult patients with complains of unilateral discharging ear were included in the study.

Results: Mostly female patients and those in the age group of 15-30 years from Bara and Parsa districts of Nepal including the areas around the Indo-Nepal border avail the services of department of ENT-HNS of National medical college and teaching hospital.

Conclusions: The delivery of ENT-HNS services to the concerned patients is insufficient and inefficient owning to various factors. The government of Nepal and India along with National medical college and teaching hospital can work together to improve the situation.
Keywords: Chronic otitis media, Ear discharge, Department of ENT-HNS

*Corresponding Author: Department of ENTHNS, National Medical College and Teaching Hospital, Birgunj-15, Parsa, Nepal, Email: amitjha086@gmail.com

\section{INTRODUCTION}

National Medical College and Teaching Hospital (NMCTH) is located in Birgunj Metropolitan City in Parsa district of Province 2 of Nepal. The weather in Parsa is of tropical type with hot summers and cool winters with occasional coldspells. Rainy season is well pronounced with high humidity for several months of the year. The population of Parsa district is $608,992 .{ }^{1}$

Discharging ear is a common symptom among patients presenting to ENT OPD (Ear, Nose and Throat Out-Patient Department) for consultation. The causes are various, the most common being Chronic Otitis Media (COM). COM is defined as a chronic inflammation of the middle ear and mastoid cavity, which presents with recurrent ear discharges or otorrhoea through a tympanic membrane perforation. It is an important cause of preventable hearing loss, especially in developing countries. $^{2}$

Chronic otitis media is one of the commonest problems encountered by an otorhinolaryngologist in his clinical practice. ${ }^{3}$ The prevalence of COM varies around the world, affecting $30 \%$ of North America's Eskimos, $4-6 \%$ of African populations and less than $1 \%$ 
of individuals in the United States and United Kingdom. ${ }^{4,5}$ Poverty, ignorance, crowded living conditions due to large families, poor sanitation, and lack of personal and environmental hygiene are some of the main factors underlying the prevalence of COM. ${ }^{6,7}$ Though, this condition doesn't seem to be common in developed countries with prevalence of less than $2 \%,{ }^{8}$ it is still a common condition to be encountered in developing nations like ours with prevalence being reported as $7.2 \%{ }^{9}$

Patients diagnosed as COM, which is a major cause for ear discharge, form the bulk of those who come to ENT OPD seeking treatment. Similarly, various surgical management options like tympanoplasty, cortical mastoidectomy and modified radical mastoidectomy are among the commonest surgical procedures performed at NMCTH. Hence, it becomes important to know the population NMCTH is catering to so that special provisions could be tailor-made for dispensing of services.

\section{METHOD}

This qualitative, descriptive study was carried out in department of ENT-HNS at National Medical College and Teaching Hospital located Birgunj-15, Parsa, Nepal for duration of one year from August 1, 2014 to July 30, 2015. Two hundred and five (205) adult patients with complains of unilateral discharging ear were included in the study. Those patients with previous ear surgery, traumatic perforation, bilateral ear discharge, deaf child and middle ear neoplasm were excluded from the study. Non-probability convenient sampling method was applied. Ethical approval for the study was obtained from Institutional Review Borard (IRB) of Institute of Medicine, Maharajgunj, Kathmandu, Nepal.

The patients, suitable for the study, were first explained about the study in detail in the language that they could understand which was mostly Bhojpuri and occasionally, Hindi, Maithili and Nepali. After the explanation, they were asked to sign the consent form after going through it. Consent forms were prepared in two languages viz. English and Nepali. Consent form was read to or translated to those who were illiterates. Then, a proforma was duly filled up with all the parameters for the study. Data thus collected was entered, stored first in Microsoft Excel for convenience and then the data were exported to SPSS 20.

\section{RESULTS}

The study was essentially limited to the adult age group. Table 1 shows that 125 out of 205 patients (61\%) were in the age group 15-30 years. 64 $(31.2 \%)$ and $16(7.8 \%)$ were from $31-45$ years and 46-60 years of age group respectively. Similarly, there are more female patients compared to the males in our setup. Of 205 patients, $137(66.8 \%)$ were females whereas only $68(33.2 \%)$ were males.

Table 1: Age and Sex Distribution of Patients $(\mathrm{n}=205)$

\begin{tabular}{|l|c|c|c|c|}
\hline \multirow{2}{*}{ Age Groups } & \multicolumn{2}{|c|}{ Sex } & \multirow{2}{*}{ Total } & \multirow{2}{*}{ p-value } \\
\cline { 2 - 3 } & $\mathbf{M}$ & $\mathbf{F}$ & & $<0.001$ \\
\hline 15-30 Years & 93 & 32 & 125 & \\
31-45 Years & 40 & 24 & 64 & \\
46-60 Years & 4 & 12 & 16 & \\
Total & 137 & 68 & 205 & \\
\hline
\end{tabular}

Further, as shown by figure 1, of 205 patients, 61 (29.8\%) were from Bara district, 57 (27.8\%) were from India, 42 (20.5\%) from Parsa district, $17(8.3 \%)$ from Sarlahi district, $13(6.3 \%)$ from Rautahat district and the remaining 15 patients were from other districts of Nepal viz Nawalparasi, Morang, Lalitpur and Dhanusa.

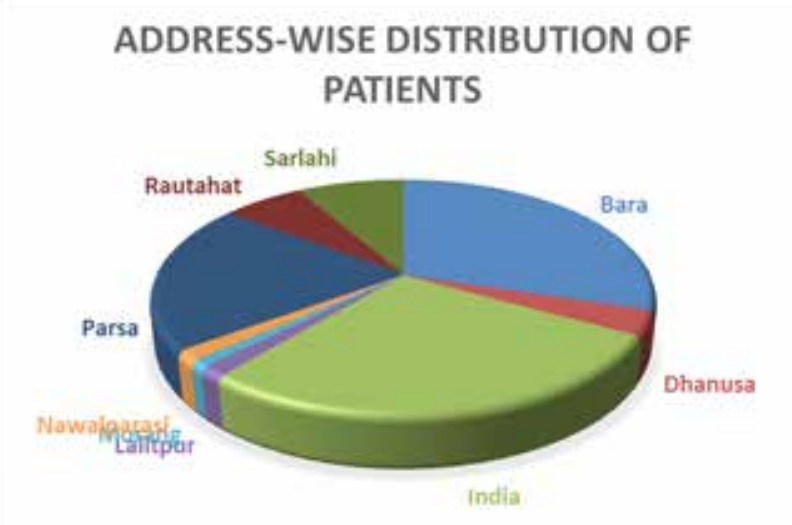

Fig 1: Address-wise distribution of patients

According to Table 2, of 205 patients, 160 (78\%) practiced Hinduism while rest $45(22 \%)$ observed Islam. 
Table 2: Distribution of Patients based on Religion

\begin{tabular}{|l|c|c|}
\hline & Frequency & Percent \\
\hline Hindu & 160 & 78.0 \\
Muslim & 45 & 22.0 \\
Total & 205 & 100.0 \\
\hline
\end{tabular}

\section{DISCUSSION}

As mentioned in the results, 125 out of 205 patients $(61 \%)$ were in the age group of $15-30$ years while 64 patients $(31.2 \%)$ and $16(7.8 \%)$ were from 3145 years and $46-60$ years of age group respectively. The mean age was 28.96 years whereas the median was 25 and standard deviation 11.201. This was comparable to the mean age calculated by Sady Salaien da Costa et al. where it was 26.3 years. ${ }^{10}$ These results show that younger persons are more concerned about their health whereas with ageing of the population, the patients tend to live with their disease. 15-30 years is the age group when people apply to join the army/police or go abroad for studies or work. Under all these circumstances, they are bound to produce certificate of medical fitness and hence, there's an increased number of patients from this age group consulting an ENT surgeon for their discharging ear.

Of 205 patients, $137(66.8 \%)$ were females whereas only $68(33.2 \%)$ were males. Similarly, out of 125 patients presenting in the age group of 15-30 years, 93 were females whereas only 32 are males. The reason behind seeking medical care in this age group was that the parents wanted their daughters to be perfectly well before getting them married off. In regions like this, where arranged marriages are common, any medical illness would cause embarrassment for the bride and her family. In the study by SadySalaimen da Constaet al., $51 \%$ of the patients were male. Similarly, $64.4 \%$ were male and $35.6 \%$ were females in the study carried out by Adhikariet al. ${ }^{11}$ Likewise, in a study carried out on 46 patients by Abou-Elhamadet al. in Egypt 31 were male and 15 female. ${ }^{12}$ In another study by Mohamad Ali Damghaniet al. in Iran, 47\% were male and $53 \%$ were female. ${ }^{13}$ Hence, the sex-wise distribution of patients of my study shows female patients outnumbering males by a good number. This is unlike any other study carried out across the globe where there were always more male patients compared to the females.
The results elaborate that most of the patients are from the Bara and Parsa districts of Nepal and from neighboring areas of India. These three locations combined accounted for $78.1 \%$ of the patients which is quite significant. The large number of patients from India also signifies the lack of a tertiary care center or even presence of an ENT surgeon in the Indian districts adjoining the Indo-Nepal border. There were a few patients from the far-flung areas as well viz. Morang, Lalitpur and Nawalparasi districts of Nepal. It was mostly due the fact that such patients were in the locality of the hospital mostly as students or job holders. Similarly, there were a few patients from adjoining districts viz. Rautahat, Sarlahi and Dhanusa as well. These geographical sites suggest that the catchment area of National Medical College expands over a radius of 50-60 $\mathrm{km}$ which is quite impressive.

Nepal is basically a Hindu country with over 90\% practicing Hinduism as their religion. Only $2 \%$ of the total population of Nepal is Muslim. Yet, $22 \%$ of the patients were visiting our ENT OPD were Muslims as Bara and Parsa districts of Nepal and the adjoining areas of India have high concentration of Muslims. Non-compliance of prescription should be expected as the author observed that some patients following Islam are reluctant to instill ear drops or nasal drops or take any medicines during the daytime of the holy month of fasting.

\section{CONCLUSION}

The catchment areas of NMCTH are impoverished with crowded living conditions and poor sanitation. Similarly, there's high humidity in this region. People living out of the cities do not have a bathroom in their house and often bathe in ponds, rivers and other water bodies. All of these result in higher prevalence and persistence of ear discharge in the population here. Mostly female patients and those in the age group of 15-30 from Bara and Parsa districts of Nepal including the areas around the Indo-Nepal border avail the services of department of ENT-HNS of NMCTH. Transportation services from the rural areas to NMCTH are not up mark. Most of the patients coming to this tertiary center are either farmers or daily wage earning laborers. They simply can't 
afford to lose a day of income for a consultation with an ENT surgeon and another few days if an operation is suggested.

Little can be done to alter the humidity in this area. Yet, there's a lot the government of Nepal and India can do to improve the sanitation and living condition of people living in the catchment area of this tertiary care hospital. NMCTH, though being a private institution, can mobilize outreach clinics focused especially for the rural areas so as to give a better life to those patients who are unlooked for and uncared. This, on the other hand, would help NMCTH earn public goodwill and trust.

\section{ACKNOWLEDGEMENT}

The author is thankful to all the patients who participated in the study and Dr. Dilip Kumar Jha and Juhi Jha for their constant support.

\section{REFERENCES}

1. Annual Report. Department of Health Services. (2010/2011) By Government of Nepal. Ministry of Health and Population. Department of Health Services. Kathmandu.

2. Chronic Suppurative otitis Media: Burden of Illness and Management Options. Child and Adolescent Health and Development. Prevention of Blindness and Deafness WHO Geneva, Switzerland. 2004.

3. Cabra J, Monux A. Efficacy of cartilage palisade tympanoplasty: randomized controlled trial. Otol Neurotol 2010; 31: 589-95.

4. Bluestone CD. Epidemiology and pathogenesis of chronic supurative otitis media: implication for prevention and treatment. Int J Pediatr Otorhinolaryngol. 1998;420:207-23.

5. Godinho RN, Goncavels TM, Nunes FB, Becker CG, Becker HM, Guimaraes RE, et al. Prevalence and impact of choronic otitis media in school age children in Brazil. First epidemiologic study concerning chronic otitis media in Latin America. Int J Pediater Otorhinolaryngol. 2001; 61:223-32.
6. Paul R, Lambert J, Mcelveen $\mathrm{T}$. Tympanoplastic surgery for chronic ear disease. Otolaryngol Head Neck Surg. 1998; 4:3108-25.

7. RA C, HH S. Cumming's Otolaryngology Head and Neck Surgery, 4th edition. 4th ed. Mosby, editor. United States. 2005.

8. Shrivastav RP. Infections of tympanic membrane and middle ear cleft. An Illustrated textbook Ear, Nose and Throat and Head and Neck Surgery, $1^{\text {st }}$ edition. WPS Pulchowk, Nepal. 2008; 36.

9. Little P, Bridges A, Guragain RPS, Prasad R, Weir N, Freidman D. Hearing impairment and ear pathology in Nepal. J Laryngol Otol. 1993; 107: 395-400.

10. Sady Selaimen da Costa, Leticia Peterson Schmidt Rosito, Cristina Dornelles. The contralateral ear in chronic otitis media. A series of 500 patients. Arch Otolaryngol Head Neck Surg. 2008; 134: 290-293.

11. Prakash Adhikari, Surendra Khanal, Rishi Bhatta, Sashi Sigdel, Dipak R. Baral ,Status of Contralateral ear in patients with Chronic Otitis Media ; Internet J Health. $2010 ; 10$ (02);15-20.

12. Kamal-Eldin Ahmed Abou-Elhamd, Ranaselan Hashem Sayed, Abd Elmateen Moussa Abou-Elhamd et al. The other ear in unilateral chronic otitis media. South Valley Medical Journal. 2004;8:1-7.

13. Mohammad Ali Danghani, Ali Barazin. Alterations in the contralateral ear in COM. In Iranian Journal of Otorhinolaryngology. No. 2, Vol 25, Serial No 71, Spring 2013. 